University of Nebraska - Lincoln

DigitalCommons@University of Nebraska - Lincoln

\title{
Biofilm Formation and Sanitizer Resistance of Escherichia coli 0157:H7 Strains Isolated from “High Event Period” Meat Contamination
}

\author{
Rong Wang \\ USDA-ARS, rong.wang@ars.usda.gov \\ Norasak Kalchayanand \\ USDA Meat Animal Research Center, norasak.kalchayanand@ars.usda.gov \\ David A. King \\ USDA-ARS, andy.king@usda.gov \\ Brandon E. Luedtke \\ USDA-ARS, luedtkebe@unk.edu \\ Joseph M. Bosilevac \\ USDA Meat Animal Research Center, mick.bosilevac@ars.usda.gov
}

See next page for additional authors

Follow this and additional works at: https://digitalcommons.unl.edu/hruskareports

Wang, Rong; Kalchayanand, Norasak; King, David A.; Luedtke, Brandon E.; Bosilevac, Joseph M.; and Arthur, Terrance M., "Biofilm Formation and Sanitizer Resistance of Escherichia coli 0157:H7 Strains Isolated from "High Event Period" Meat Contamination" (2014). Roman L. Hruska U.S. Meat Animal Research Center. 400.

https://digitalcommons.unl.edu/hruskareports/400

This Article is brought to you for free and open access by the U.S. Department of Agriculture: Agricultural Research Service, Lincoln, Nebraska at DigitalCommons@University of Nebraska - Lincoln. It has been accepted for inclusion in Roman L. Hruska U.S. Meat Animal Research Center by an authorized administrator of DigitalCommons@University of Nebraska - Lincoln. 


\section{Authors}

Rong Wang, Norasak Kalchayanand, David A. King, Brandon E. Luedtke, Joseph M. Bosilevac, and Terrance M. Arthur 


\title{
Research Note
}

\section{Biofilm Formation and Sanitizer Resistance of Escherichia coli 0157:H7 Strains Isolated from "High Event Period" Meat Contamination ${ }^{\dagger}$}

\author{
RONG WANG,* NORASAK KALCHAYANAND, DAVID A. KING, BRANDON E. LUEDTKE, JOSEPH M. BOSILEVAC, AND \\ TERRANCE M. ARTHUR
}

U.S. Department of Agriculture, Agricultural Research Service, Roman L. Hruska U.S. Meat Animal Research Center, Clay Center, Nebraska 68933-0166, USA

MS 14-253: Received 29 May 2014/Accepted 6 July 2014

\begin{abstract}
In the meat industry, a "high event period" (HEP) is defined as a time period during which commercial meat plants experience a higher than usual rate of Escherichia coli $\mathrm{O} 157: \mathrm{H} 7$ contamination. Genetic analysis indicated that within a HEP, most of the E. coli O157:H7 strains belong to a singular dominant strain type. This was in disagreement with the current beef contamination model stating that contamination occurs when incoming pathogen load on animal hides, which consists of diverse strain types of $E$. coli O157:H7, exceeds the intervention capacity. Thus, we hypothesize that the HEP contamination may be due to certain in-plant colonized E. coli $\mathrm{O} 157: \mathrm{H} 7$ strains that are better able to survive sanitization through biofilm formation. To test our hypothesis, a collection of 45 E. coli $\mathrm{O} 157: \mathrm{H} 7$ strains isolated from HEP beef contamination incidents and a panel of 47 E. coli $\mathrm{O} 157: \mathrm{H} 7$ strains of diverse genetic backgrounds were compared for biofilm formation and sanitizer resistance. Biofilm formation was tested on 96-well polystyrene plates for 1 to 6 days. Biofilm cell survival and recovery growth after sanitization were compared between the two strain collections using common sanitizers, including quaternary ammonium chloride, chlorine, and sodium chlorite. No difference in "early stage" biofilms was observed between the two strain collections after incubation at 22 to $25^{\circ} \mathrm{C}$ for 1 or 2 days. However, the HEP strains demonstrated significantly higher potency of "mature" biofilm formation after incubation for 4 to 6 days. Biofilms of the HEP strains also exhibited significantly stronger resistance to sanitization. These data suggest that biofilm formation and sanitization resistance could have a role in HEP beef contamination by E. coli O157:H7, which highlights the importance of proper and complete sanitization of food contact surfaces and food processing equipment in commercial meat plants.
\end{abstract}

Shiga toxin-producing Escherichia coli are important foodborne pathogens that have been implicated in numerous outbreaks and human illness. E. coli $\mathrm{O} 157: \mathrm{H} 7$ is the most commonly identified Shiga toxin-producing E. coli serotype responsible for multiple foodborne outbreaks and cases of clinical disease, including bloody diarrhea or other more severe diseases, such as hemolytic uremic syndrome. Therefore, this pathogen has been regulated by the U.S. Department of Agriculture (USDA) as an adulterant in the nation's beef supply.

In the meat industry, foodborne pathogen contamination poses a serious public health concern and often results in significant financial loss due to product recalls. Beef trim contamination by E. coli $\mathrm{O} 157: \mathrm{H} 7$ in commercial meat plants usually occurs at low-level baselines; however, multiple positive test results of E. coli O157:H7 in trim samples can be

\footnotetext{
* Author for correspondence. Tel: 402-762-4228; Fax: 402-762-4149; E-mail: rong.wang@ars.usda.gov.

$\uparrow$ Product names are necessary to report factually on available data; however, the U.S. Department of Agriculture neither guarantees nor warrants the standard of the product, and the use of the name by USDA implies no approval of the product to the exclusion of others that may also be suitable.
}

clustered within a short production period, which is referred to as the "high event period" (HEP). According to the USDA Food Safety and Inspection Service, "HEPs are periods in which slaughter establishments experience a high rate of $E$. coli $\mathrm{O} 157: \mathrm{H} 7$ (or Shiga toxin-producing E. coli organisms or virulence markers) in trim samples from production lots containing the same source materials" (23). Currently, the precise cause or contamination source responsible for HEPs in commercial establishments remains unknown.

Available studies $(2,3,5-8,18)$ have identified that pathogens on animal hides are the main source of carcass contamination at meat processing plants when the incoming pathogen load on hides exceeds the capacity of the in-plant antimicrobial interventions. Therefore, it had been assumed that the cause of HEPs would follow this traditional meat contamination model as well, so that the E. coli $\mathrm{O} 157: \mathrm{H} 7$ strains isolated from HEPs would be a direct result of bacterial contamination on the hides of the incoming cattle, and thus should also reflect the high genetic diversity seen commonly on animal hides. However, our previous study (1) of genetic analysis with pulse-field gel electrophoresis genome typing indicated that the E. coli $\mathrm{O} 157: \mathrm{H} 7$ strains isolated from HEP contaminations in raw beef products 
consisted of a singular predominant O157 strain type within each HEP, even though these strains were collected across multiple product lots and harvested over time spans representing as many as 2,000 head of processed cattle. These results were in disagreement with the traditional model of beef contamination as strain types obtained from hides of incoming cattle were analyzed on multiple occasions and always consisted of a widely diverse strain set $(2,4)$. The contradiction in these observations led us to hypothesize that HEPs might be the result of contamination occurring after carcasses exit the kill-floor. If so, one logical explanation would be that the HEP contamination is due to certain in-plant colonized E. coli O157:H7 strains that are better able to survive the exposure to sanitizers, likely through the formation of biofilms, since bacteria at biofilm stage usually are much more resistant to sanitizing agents than planktonic cells of the same species. To test our hypothesis, in the present study we used a subset of 45 E. coli $\mathrm{O} 157: \mathrm{H7}$ strains isolated from HEP beef product contamination and compared them to a group of $47 \mathrm{E}$. coli O157:H7 control strains (MSQRU O157:H7 Diversity Panel) in terms of biofilm-forming ability and sanitizer susceptibility to determine if biofilm formation and the subsequent sanitizer resistance could have a role in the HEP beef contamination by E. coli $\mathrm{O} 157: \mathrm{H} 7$ in commercial meat processing plants.

\section{MATERIALS AND METHODS}

Bacterial strains, culture conditions, and curli and cellulose expression. The testing strains of the two collections included 45 strains of $E$. coli $\mathrm{O} 157: \mathrm{H} 7$ isolated from HEPs and $47 E$. coli $\mathrm{O} 157: \mathrm{H} 7$ strains of the U.S. Meat Animal Research Center O157 diversity control panel that were isolated from animal hide swabs of beef cattle during harvest at the processing plants. The HEP isolates were strains representing the genotypes associated with 14 HEPs and were recovered from enrichments as described previously (1). The U.S. Meat Animal Research Center diversity panel represents the breadth of E. coli $\mathrm{O} 157: \mathrm{H} 7$ pulse-field gel electrophoresis types from over 1,000 cattle hide samples collected previously (4).

For biofilm assays and sanitization studies, bacterial broth cultures at stationary phase were prepared in Lennox broth (LB; Acumedia Manufacturers, Baltimore, MD) without salt (LB-NS) as described previously (24), and then were further diluted in fresh sterile LB-NS medium for each experiment. The expressions of curli and cellulose fimbriae by the above strains, the two bacterial extracellular polymeric substances associated with bacterial biofilm-forming abilities, and sanitizer resistance were tested as described previously (25) using Congo Red Indicator plates and LB agar plates containing calcoflour dye, respectively.

Sanitizers. Vanquish (Dawn Chemical Corp., Milwaukee, WI) is a quaternary ammonium chloride (QAC)-based commercial sanitizer authorized by the USDA as category D2 for use in meat, poultry, and other food processing plants. Vanquish was 1:171 diluted in sterile distilled water as recommended by the manufacturer, which contains $300 \mathrm{ppm}$ of active ingredients of an alkylbenzyldimethylammonium chloride mixture, to be used for QAC treatments throughout the study. Chlorine solution at the final concentration of $200 \mathrm{ppm}$ was prepared in sterile distilled water from commercial germicidal bleach (Clorox, Oakland, CA) as described previously (24), and the chlorine level in the solution was confirmed using the High Range Free Chlorine Test Strips (LaMotte Co., Chestertown, MD).
Pro-Oxine (DanMar, Arlington, TX), a refined blend of oxychloro species containing purified sodium chlorite, is a broad-spectrum fungicidal and bactericidal sanitizer. It has been applied as a terminal sanitizing rinse for hard nonporous food contact surfaces and food processing equipment. Its mechanism of action involves chlorine dioxide production after product activation, resulting in enhanced antimicrobial activities against biofilms by common foodborne pathogens. A working solution containing $50 \mathrm{ppm}$ of available chlorine dioxide was prepared following the manufacturer's instructions. The concentrations of total available and free chlorine dioxide were confirmed using a chlorine dioxide test kit provided by the manufacturer.

Biofilm formation on 96-well polystyrene plates. The crystal violet (CV) staining assay for biofilm measurement was described previously (24). Briefly, an overnight culture of each $E$. coli $\mathrm{O} 157: \mathrm{H} 7$ strain that contained approximately $5 \times 10^{8} \mathrm{CFU} / \mathrm{ml}$ bacterial cells was 100-fold diluted in sterile LB-NS broth, added to 96-well flat-bottom polystyrene plates (Costar, Corning, NY) at $200 \mu \mathrm{l}$ per well, and incubated statically for 1 to 6 days at 22 to $25^{\circ} \mathrm{C}$. Wells containing sterile LB-NS broth only were included as negative controls. After incubation, supernatants were carefully removed from each well by aspiration, and the plates were washed with $200 \mu \mathrm{l}$ per well of sterile phosphate-buffered saline (PBS $1 \times$, $\mathrm{pH}$ 7.2) to remove loosely attached cells. The plates were air dried for $5 \mathrm{~min}$ and the attached cells were stained with $200 \mu \mathrm{l}$ per well of $0.1 \% \mathrm{CV}$ for $20 \mathrm{~min}$. The plates were washed again with PBS, air dried, and the remaining CV was dissolved in $200 \mu \mathrm{l}$ per well of $85 \%$ ethanol. The amount of the extracted $\mathrm{CV}$ in each well was determined by absorbance measurement at $570 \mathrm{~nm}$ using a microplate reader (Molecular Devices, Sunnyvale, CA). For each strain at each incubation time period, the absorbance data were averaged from at least 4 replicate wells and each experiment was performed at least twice using independent cultures.

Bacterial survival and recovery in biofilms treated with sanitizers. The three types of sanitizers described above were applied to test the survival and recovery capability of the two groups of E. coli $\mathrm{O} 157: \mathrm{H} 7$ strains in biofilms. For the feasibility of simultaneously testing a large number of E. coli $\mathrm{O} 157: \mathrm{H} 7$ strains in terms of bacterial survival and subsequent recovery after each sanitization treatment, a 96-well plate absorbance assay was applied to assess viable E. coli O157:H7 cell growth in Dey/Engley broth (BD, Franklin Lakes, NJ) after sanitization. To do so, all strains were allowed to form biofilms on 96-well polystyrene plates for 3 days as described above. At the end of the incubation period, bacterial supernatants were removed gently by aspiration, and the plates were washed with $200 \mu \mathrm{l}$ per well of sterile PBS to remove the residual planktonic cells or any loosely attached cells. The plates were air dried for 5 minutes, and then the wells were filled with $200 \mu \mathrm{l}$ of sterile PBS or the prepared sanitizers. The PBS or sanitizer solutions were removed by aspiration after a 1-min incubation, then all samples were neutralized immediately by adding $200 \mu \mathrm{l}$ per well of sterile Dey/Engley broth. The plates were incubated at 22 to $25^{\circ} \mathrm{C}$ for 18 to $20 \mathrm{~h}$, and the absorbance of each well was measured at $433 \mathrm{~nm}$ using the microplate reader. Samples treated with sterile PBS were used as positive controls and sterile Dey/Engley broth alone served as negative controls. The absorbance data were averaged from at least 4 replicate wells and each sanitizer was tested at least twice using independent cultures.

Statistical analysis. The absorbance data of biofilm formation $\left(A_{570 \mathrm{~nm}}\right)$ on each day or bacterial recovery growth $\left(A_{433 \mathrm{~nm}}\right)$ after exposure to each sanitizer were stratified into frequency 
TABLE 1. Frequency distribution of E. coli O157:H7 strains selected from diversity control panel or isolated from "high event period"' (HEP) beef contaminations classified by the ability to form biofilms on 96-well polystyrene plates

\begin{tabular}{|c|c|c|c|c|c|c|c|}
\hline \multirow[b]{2}{*}{ Day } & \multirow[b]{2}{*}{ Strain } & \multicolumn{5}{|c|}{ No. $(\%)$ of strains recovered in each $A_{570 \mathrm{~nm}}$ group $^{a}$} & \multirow[b]{2}{*}{$P^{b}$} \\
\hline & & $<1.0$ & $1.0-1.39$ & $1.4-1.79$ & $1.8-2.19$ & $>2.2$ & \\
\hline \multirow[t]{2}{*}{1} & Control & $46(97.9)$ & 0 & 0 & $1(2.1)$ & 0 & \\
\hline & HEP & 45 (100) & 0 & 0 & 0 & 0 & 0.3252 \\
\hline \multirow[t]{2}{*}{2} & Control & $42(89.4)$ & $3(6.4)$ & $1(2.1)$ & 0 & $1(2.1)$ & \\
\hline & HEP & $41(91.1)$ & 0 & $1(2.2)$ & 0 & $3(6.7)$ & 0.2647 \\
\hline \multirow[t]{2}{*}{3} & Control & $5(10.6)$ & $9(19.2)$ & $19(40.4)$ & $6(12.8)$ & $8(17)$ & \\
\hline & HEP & $9(20)$ & 8 (17.8) & $9(20)$ & $7(15.5)$ & $12(26.7)$ & 0.2303 \\
\hline \multirow[t]{2}{*}{4} & Control & 0 & $11(23.4)$ & $20(42.6)$ & $6(12.8)$ & $10(21.2)$ & \\
\hline & HEP & 0 & 7 (15.5) & 3 (6.7) & $16(35.6)$ & $19(42.2)$ & 0.0001 \\
\hline \multirow[t]{2}{*}{5} & Control & $3(6.4)$ & $18(38.3)$ & $8(17)$ & $4(8.5)$ & $14(29.8)$ & \\
\hline & HEP & $5(11.1)$ & $3(6.7)$ & $8(17.8)$ & $11(24.4)$ & $18(40)$ & 0.0048 \\
\hline \multirow[t]{2}{*}{6} & Control & $26(55.3)$ & $6(12.8)$ & $6(12.8)$ & $1(2.1)$ & 8 (17) & \\
\hline & HEP & 12 (26.7) & 7 (15.5) & $10(22.2)$ & $8(17.8)$ & $8(17.8)$ & 0.0202 \\
\hline
\end{tabular}

${ }^{a}$ Each strain was allowed to form biofilms on 96-well polystyrene plates in LB-NS medium at 22 to $25^{\circ} \mathrm{C}$ for 1 to 6 days; $n=4$.

${ }^{b}$ Statistical analysis of frequency distributions was performed using the Pearson $\chi^{2}$ statistic. $P$ values lower than 0.05 were considered statistically significant.

classes. Cross tabulation tables comparing the frequency of the strain distribution among the frequency classes in the HEP and control strain collections were generated using the PROC FREQ procedure of SAS (Cary, NC). The distributions were compared using the Pearson $\chi^{2}$ statistic, which was calculated using the CHISQ option. A probability of 0.05 was used for all judgments of statistical significance.

\section{RESULTS AND DISCUSSION}

Bacterial biofilms associated with clinical and industrial environments have a tremendous impact on public health. It has been shown that bacteria can form biofilms in many different areas of food processing plants; thus, biofilm formation by foodborne pathogens is a serious food safety concern because the detached biofilm cells may lead to cross-contamination in food products (17). The potential of cross-contamination at commercial meat plants could be enhanced if the contact surfaces and equipment are not completely cleaned and sanitized. The improperly sanitized contact surfaces, such as tables, cutting boards, conveyor belts, and other meat processing tools, could reintroduce bacteria to meat products. Gill et al. $(12,13)$ evaluated and compared bacterial populations on beef carcasses and primal cuts before entry into the fabrication process and after the exit of the process line. Their studies reported significant increases of E. coli and coliform counts on meat products after exiting the process line, which was attributed to the contact with cutting surfaces. These results indicated that bacteria that survived the cleaning and sanitizing process would pose a potential risk of meat contamination.

Due to the findings from our previous study (1) that each E. coli O157:H7 HEP had one dominant strain genotype responsible for most of the contamination instead of a wide variety of strains as observed on animal hides, we hypothesize that in-plant bacterial biofilm formation and the subsequent sanitizer resistance may have roles in the HEP phenomenon. Therefore, this study investigated the differences between the two collections of $E$. coli $\mathrm{O} 157: \mathrm{H} 7$ strains with respect to their capability of biofilm formation and the resistance to common sanitizing agents. We first tested the expression of exopolysaccharide cellulose and curli fimbriae by each $E$. coli O157:H7 strain as these two types of extracellular structures were well documented not only to increase bacterial biofilmforming ability, but also to enhance biofilm resistance to sanitization $(9,19,22,27)$. Within the 45 strains isolated from HEPs, 11 and 6 strains were tested positive for curli and cellulose expression, respectively, whereas 14 and 8 strains were positive for curli and cellulose expression, respectively, within the 47 control strains.

Biofilm formation on 96-well polystyrene plates was measured with $\mathrm{CV}$ staining as a phenotype screening to compare the biofilm-forming ability by the HEP and the diversity control strains (Table 1). Based on the absorbance measurements at $570 \mathrm{~nm}\left(A_{570 \mathrm{~nm}}\right)$, the examined strains in each collection were classified into five groups with respect to biofilm-forming ability: group 1 (the strongest, $A_{570 \mathrm{~nm}}>$ 2.2), group 2 (strong, $1.8 \leq A_{570 \mathrm{~nm}} \leq 2.19$ ), group 3 (moderate, $1.4 \leq A_{570 \mathrm{~nm}} \leq 1.79$ ), group 4 (weak, $1.0<$ $A_{570 \mathrm{~nm}} \leq 1.39$ ), and group 5 (the weakest, $A_{570 \mathrm{~nm}}<1.0$ ). Wells containing sterile LB-NS medium only yielded average $A_{570 \mathrm{~nm}}$ values lower than 0.55 .

There was no significant difference in biofilm formation between the two strain collections after 1 or 2 days of incubation, as the majority of the strains in each collection formed only the weakest biofilms or exhibited no significant difference of absorbance measurement from medium control wells. Starting on day 3, a higher tendency of biofilm development by the HEP strains was observed even though the difference was not statistically significant, as $12(26.7 \%)$ and $7(15.5 \%)$ of the HEP strains formed the strongest (group 1) and strong (group 2) biofilms, respectively, compared with $8(17 \%)$ and $6(12.8 \%)$ of the strains in the diversity control collection that fell into the same groups $(P$ $=0.2303$ ). 
Significant differences between the two strain sets were observed clearly in mature biofilms after prolonged incubation for 4, 5, and 6 days. On day 4, the strongest and strong biofilms were observed in 19 (42.2\%) and 16 $(35.6 \%)$ of the HEP strains, respectively, compared with only $10(21.2 \%)$ and $6(12.8 \%)$ of the control strains $(P=$ $0.0001)$. The difference of biofilm-forming capability also was evident after 5 days of incubation. Of the HEP strains, $18(40 \%)$ and $11(24.4 \%)$ were the strongest and strong biofilm formers, respectively, compared with only 14 $(29.8 \%)$ and $4(8.5 \%)$ of the control strains $(P=$ $0.0048)$. On day $6,26(55.3 \%)$ of the control strains, more than twice that of the HEP strains (26.7\%, 12 strains), yielded average $A_{570 \mathrm{~nm}}$ values lower than 1.0 (group 5, the weakest biofilms), suggesting biofilm detachment after prolonged incubation. Meanwhile, a significant difference of biofilm mass still was observed between the two strain collections, as higher proportions of the HEP strains occurred in all four groups that formed biofilms at various levels $(P=0.0202)$, indicating a stronger attachment and longer persistence of biofilms by the HEP strains. Collectively, these data indicated that the HEP strain collection had stronger biofilm-forming ability, since the HEP strains consistently occurred with higher frequency in the more potent biofilm development groups compared to the control strains after prolonged incubation for mature biofilm formation.

Notably, a correlation between positive curli and cellulose expression and strong biofilm-forming ability was detected in both strain collections at each time point. It has been known that biofilm formation could be mediated by the combination of bacterial surface structures expressed at various levels dependent upon the environmental conditions encountered by the bacteria, and curli fimbriae as well as exopolysaccharide cellulose have been well associated with biofilm formation $(9,19,22,24,25,27)$. However, in the present study no significant difference was detected between the two strain collections in terms of the numbers of strains that exhibited positive curli and cellulose expressions. Indeed, the diversity control group had a slightly higher number of strains that showed positive expression of the two bacterial cell surface structures. Therefore, the positive curli and cellulose expression was not the determining factor in our observation that overall the HEP strains demonstrated higher potential of biofilm formation. Numerous studies have indicated that biofilm formation could be affected in complex ways by a combination of physiological and environmental factors. Mechanisms, such as the regulation of bacterial quorum sensing system, chemotaxis, flagellar synthesis, and other motility genes, were involved in bacterial biofilm formation at various levels under different conditions (21). Mechanisms that underlie the higher biofilm-forming ability by the HEP strains remain to be elucidated.

We further explored biofilm cell survival and recovery growth after biofilms being treated with the different sanitizers. Our selection of the absorbance assay on 96well plates to measure bacterial recovery growth instead of the traditional colony enumeration method was based upon the need to develop a quick screening assay for a large amount of samples. The 96-well plate absorbance assay allows for larger scale and more economical experiments, as opposed to the traditional colony enumeration method on agar plates, which would accommodate much fewer strains, but meanwhile, much more time and material consuming and labor intensive. Conversely, the absorbance assay was based on a positive correlation between bacterial cell densities and medium absorbance values (data not shown), because the medium color shift of the Dey/Engley broth from purple to yellow as a result of carbohydrate fermentation from bacterial growth could be quantified conveniently by absorbance measurement at $433 \mathrm{~nm}$ using the microplate reader. Wells containing sterile Dey/Engley broth only served as negative controls, which yielded average $A_{433} \mathrm{~nm}$ values lower than 1.39. Biofilm samples treated with sterile PBS as positive controls yielded average $A_{433 \mathrm{~nm}}$ values between 2.19 and 2.25 after overnight incubation. Based on the $A_{433} \mathrm{~nm}$ measurements, the survival and subsequent growth of the examined strains after each treatment were classified into four groups: group 1 (strong, $A_{433 \mathrm{~nm}}>2.2$ ), group 2 (moderate, $1.8 \leq A_{433 \mathrm{~nm}} \leq 2.19$ ), group 3 (weak, $1.4 \leq A_{433 \mathrm{~nm}} \leq 1.79$ ), and group 4 (background, $A_{433} \mathrm{~nm} \leq 1.39$ ).

Overall, high percentages of the strains in each collection exhibited recovery growth at various levels after sanitization treatment. This was in agreement with our previous findings that even though treatments with the commonly used sanitizers at recommended concentrations significantly reduced viable biofilm cells, the treatments were unable to eliminate viable bacteria completely and the effectiveness of sanitization appeared to be highly straindependent $(24,25)$. A recent study (10) evaluating the activities of sodium hypochlorite, sodium hydroxide, and benzalkonium chloride against Salmonella biofilms also found that none of these agents was able to achieve a complete eradication of mature Salmonella biofilms. Similar results were obtained from the current study with the absorbance assay, and our data indicated that even though bacterial survival and recovery was strain-dependent, the HEP strain collection overall demonstrated significantly higher sanitization resistance and stronger recovery growth after each treatment (Table 2). After the 300-ppm QAC treatment, $16(35.6 \%)$ and $29(64.4 \%)$ of the HEP strains appeared to be moderate and weak survivors, respectively, compared with $6(12.8 \%)$ and $26(55.3 \%)$ of the control strains $(P=0.0002)$. Interestingly, the exact same pattern of results was observed after exposure to $200 \mathrm{ppm}$ of chlorine solution, which also is a commonly applied treatment in the food industry (Table 2). After exposure to $50 \mathrm{ppm}$ of Pro-Oxine (sodium chlorite), no strains were strong survivors. Only one HEP strain exhibited moderate survival and recovery capability, while 29 (64.5\%) of the HEP strains yielded $A_{433} \mathrm{~nm}$ values between 1.40 and 1.79 (weak survivor) compared with $20(42.5 \%)$ of the control strains. Meanwhile, $27(57.5 \%)$ of the control strains belonged to the background group compared with 15 (33.3\%) of the HEP strains $(P=0.0488)$. These frequency distributions of the strains in the different "survivor 
TABLE 2. Frequency distribution of E. coli O157:H7 strains selected from diversity control panel or isolated from "high event period" $(H E P)$ beef contaminations classified by the ability of recovery growth after sanitization

\begin{tabular}{llccccc}
\hline & & \multicolumn{3}{c}{ No. (\%) of strains recovered in each $A_{433 \mathrm{~nm}}$ group $^{b}$} & \multirow{2}{*}{$P^{c}$} \\
\cline { 3 - 5 } Sanitizer $^{a}$ & Strain & $1.0-1.39$ & $1.4-1.79$ & $1.8-2.19$ & $>2.2$ & \\
\hline \multirow{2}{*}{ QAC } & Control & $14(29.8)$ & $26(55.3)$ & $6(12.8)$ & $1(2.1)$ & \\
\multirow{2}{*}{ Chlorine } & HEP & 0 & $29(64.4)$ & $16(35.6)$ & 0 & 0.0002 \\
& Control & $14(29.8)$ & $26(55.3)$ & $6(12.8)$ & $1(2.1)$ & \\
\multirow{2}{*}{ ProOxine } & HEP & 0 & $29(64.4)$ & $16(35.6)$ & 0 & 0.0002 \\
& Control & $27(57.5)$ & $20(42.5)$ & 0 & 0 & \\
& HEP & $15(33.3)$ & $29(64.5)$ & $1(2.2)$ & 0 & 0.0488 \\
\hline
\end{tabular}

${ }^{a}$ QAC, chlorine, or Pro-Oxine solutions were prepared in sterile distilled water and used at recommended final concentrations of 300, 200, and $50 \mathrm{ppm}$, respectively.

${ }^{b}$ Biofilms by E. coli $\mathrm{O} 157: \mathrm{H} 7$ strains on 96-well polystyrene plates were treated with each sanitizer and bacterial recovery growth after sanitization in Dey/Engley broth was measured with absorbance values obtained at the 433-nm wavelength; $n=4$.

${ }^{c}$ Statistical analysis of frequency distributions was performed using the Pearson $\chi^{2}$ statistic. $P$ values lower than 0.05 were considered statistically significant.

categories" indicated that the HEP strain collection had a stronger tolerance to the common sanitizers and higher recovery capability compared with the control panel strains.

It is noteworthy that strains with stronger biofilmforming abilities also exhibited higher resistance to sanitization as well as recovery capability in the present study (data not shown). This is consistent with previous findings that bacteria at biofilm stage generally are more resistant to physical and chemical treatments due to the strong three-dimensional biofilm structures and the additional protections provided by the multiple layers of bacterial cells with well-expressed extracellular substances $(24,25)$. For our sanitization study, we selected biofilms developed for 3 days, since biofilm maturity and well expressed cell surface structure are important for protection. The majority of the examined strains developed significant amounts of biofilm mass at day 3, except a number of HEP strains that did not reach the peak of biofilm development until day 4 . On the other hand, on day 3 even though the HEP strains started showing a tendency of higher biofilm formation, the two strain collections had not yet exhibited significant differences in biofilm measurement; thus, the comparison of sanitization resistance and recovery growth would not be solely dependent upon the significantly higher biofilm mass developed by the HEP strains after prolonged incubation. Nevertheless, based on the observation that 3day biofilms by HEP strains exhibited higher sanitizer resistance and stronger recovery growth, it can be reasonably speculated that after prolonged incubation for 4, 5, or 6 days, while the HEP strains formed even significantly higher biofilm mass than the control strains, the HEP strain collection would obtain even higher tolerance and stronger survival and recovery capability against sanitization compared to the control strains. This also has been well recognized in the research field that the sensitivity of biofilms to sanitization is related to the age of biofilms, since the diffusion of the sanitizers through the biofilm 3-dimensional architectures would be less efficient as biofilm maturation increases $(10,20)$. Thus, proper sanitization should be performed at the early stage to prevent biofilm maturation. In addition to our current observation, further studies are needed to investigate sanitizer efficacy that targets more mature E. coli O157:H7 biofilms for maximal bacterial deactivation.

Besides the factor of biofilm mass development, bacterial surface extracellular polymeric substances expression has been reported not only to be associated with high biofilm-forming ability, but also to increase bacterial sanitizer resistance (20) as well as to enhance bacterial survival in the presence of toxic compounds, such as nickel (16). However, in the present study, the numbers of strains expressing cellulose and curli fimbriae were not significantly different between the two strain collections; thus, these two types of bacterial extracellular polymeric substances expression did not seem to be a determining factor for the higher sanitization resistance of the HEP strains. Interestingly, high resistance and recovery also was observed in some strains with relatively low biofilm formation (data not shown) in each sample collection, which was likely due to the expression of certain specific sanitizer resistance genes, such as the qac genes $(11,14,15$, 26). In these cases, differential gene regulation or separate pathways could be initiated in response to sanitization and to other signals, for example, low nutrition supply that triggers cell adhesion and biofilm mass development. Therefore, besides biofilm formation, the exact mechanism responsible for the higher sanitization resistance and stronger survival capability of the HEP strains requires further studies.

In summary, this comparative study indicated that the E. coli $\mathrm{O} 157: \mathrm{H} 7$ strains isolated from HEP beef contaminations in commercial plants had significantly higherbiofilm forming ability and lower sanitizer susceptibility compared to the diversity control strains. Thus, our study suggested a new meat contamination model, in which biofilm formation and sanitizer resistance may have a role in HEP meat contamination. Even though the exact mechanisms that underlie these differences remain to be 
elucidated, these results provided a novel dimension towards our understanding of the HEP contamination phenomenon that concerns many commercial meat plants, and may help develop strategies for the meat industry to mitigate the risk of transferring foodborne pathogens to meat products.

\section{ACKNOWLEDGMENTS}

We thank Sydney Brodrick, Lawnie Luedtke, and Alberto O. Alvarado for technical support, and Jody Gallagher for secretarial assistance.

\section{REFERENCES}

1. Arthur, T. M., J. L. Bono, and N. Kalchayanand. 2014. Characterization of Escherichia coli 0157:H7 strains from contaminated raw beef trim during "high event periods." Appl. Environ. Microbiol. 80: 506-514.

2. Arthur, T. M., J. M. Bosilevac, D. M. Brichta-Harhay, M. N. Guerini, N. Kalchayanand, S. D. Shackelford, T. L. Wheeler, and M. Koohmaraie. 2007. Transportation and lairage environment effects on prevalence, numbers, and diversity of Escherichia coli O157:H7 on hides and carcasses of beef cattle at processing. J. Food Prot. 70: 280-286.

3. Arthur, T. M., J. M. Bosilevac, X. Nou, S. D. Shackelford, T. L. Wheeler, M. P. Kent, D. Jaroni, B. Pauling, D. M. Allen, and M. Koohmaraie. 2004. Escherichia coli $\mathrm{O} 157$ prevalence and enumeration of aerobic bacteria, Enterobacteriaceae, and Escherichia coli $\mathrm{O} 157$ at various steps in commercial beef processing plants. J. Food Prot. 67:658-665.

4. Arthur, T. M., J. M. Bosilevac, X. Nou, S. D. Shackelford, T. L. Wheeler, and M. Koohmaraie. 2007. Comparison of the molecular genotypes of Escherichia coli O157:H7 from the hides of beef cattle in different regions of North America. J. Food Prot. 70:1622-1626.

5. Barkocy-Gallagher, G. A., T. M. Arthur, M. Rivera-Betancourt, X. Nou, S. D. Shackelford, T. L. Wheeler, and M. Koohmaraie. 2003. Seasonal prevalence of Shiga toxin-producing Escherichia coli, including O157:H7 and non-O157 serotypes, and Salmonella in commercial beef processing plants. J. Food Prot. 66:1978-1986.

6. Bosilevac, J. M., T. M. Arthur, J. L. Bono, D. M. Brichta-Harhay, N. Kalchayanand, D. A. King, S. D. Shackelford, T. L. Wheeler, and M. Koohmaraie. 2009. Prevalence and enumeration of Escherichia coli O157:H7 and Salmonella in U.S. abattoirs that process fewer than 1,000 head of cattle per day. J. Food Prot. 72:1272-1278.

7. Bosilevac, J. M., T. M. Arthur, T. L. Wheeler, S. D. Shackelford, M. Rossman, J. O. Reagan, and M. Koohmaraie. 2004. Prevalence of Escherichia coli $\mathrm{O} 157$ and levels of aerobic bacteria and Enterobacteriaceae are reduced when hides are washed and treated with cetylpyridinium chloride at a commercial beef processing plant. $J$. Food Prot. 67:646-650.

8. Brichta-Harhay, D. M., M. N. Guerini, T. M. Arthur, J. M. Bosilevac, N. Kalchayanand, S. D. Shackelford, T. L. Wheeler, and M. Koohmaraie. 2008. Salmonella and Escherichia coli O157:H7 contamination on hides and carcasses of cull cattle presented for slaughter in the United States: an evaluation of prevalence and bacterial loads by immunomagnetic separation and direct plating methods. Appl. Environ. Microbiol. 74:6289-6297.

9. Collinson, S. K., S. C. Clouthier, J. L. Doran, P. A. Banser, and W. W. Kay. 1996. Salmonella enteritidis agfBAC operon encoding thin, aggregative fimbriae. J. Bacteriol. 178:662-667.

10. Corcoran, M., D. Morris, N. De Lappe, J. O'Connor, P. Lalor, P. Dockery, and M. Cormican. 2014. Commonly used disinfectants fail to eradicate Salmonella enterica biofilms from food contact surface materials. Appl. Environ. Microbiol. 80:1507-1514.

11. Gaze, W. H., L. Zhang, N. A. Abdouslam, P. M. Hawkey, L. CalvoBado, J. Royle, H. Brown, S. Davis, P. Kay, A. B. Boxall, and E. M. Wellington. 2011. Impacts of anthropogenic activity on the ecology of class 1 integrons and integron-associated genes in the environment. ISME J. 5:1253-1261.
12. Gill, C. O., M. Badoni, and J. C. McGinnis. 1999. Assessment of the adequacy of cleaning of equipment used for breaking beef carcasses. Int. J. Food Microbiol. 46:1-8.

13. Gill, C. O., J. C. McGinnis, and J. Bryant. 2001. Contamination of beef chucks with Escherichia coli during carcass breaking. J. Food Prot. 64:1824-1827.

14. Gillings, M. R., D. Xuejun, S. A. Hardwick, M. P. Holley, and H. W. Stokes. 2009. Gene cassettes encoding resistance to quaternary ammonium compounds: a role in the origin of clinical class 1 integrons? ISME J. 3:209-215.

15. Heir, E., G. Sundheim, and A. L. Holck. 1999. The qacG gene on plasmid pST94 confers resistance to quaternary ammonium compounds in staphylococci isolated from the food industry. J. Appl. Microbiol. 86:378-388.

16. Hidalgo, G., X. Chen, A. G. Hay, and L. W. Lion. 2010. Curli produced by Escherichia coli PHL628 provide protection from $\mathrm{Hg}(\mathrm{II})$. Appl. Environ. Microbiol. 76:6939-6941.

17. Marouani-Gadri, N., G. Augier, and B. Carpentier. 2009. Characterization of bacterial strains isolated from a beef-processing plant following cleaning and disinfection-influence of isolated strains on biofilm formation by Sakaï and EDL 933 E. coli O157:H7. Int. J. Food Microbiol. 133:62-67.

18. Nou, X., M. Rivera-Betancourt, J. M. Bosilevac, T. L. Wheeler, S. D. Shackelford, B. L. Gwartney, J. O. Reagan, and M. Koohmaraie. 2003. Effect of chemical dehairing on the prevalence of Escherichia coli $\mathrm{O} 157: \mathrm{H} 7$ and the levels of aerobic bacteria and Enterobacteriaceae on carcasses in a commercial beef processing plant. J. Food Prot. 66:2005-2009.

19. Römling, U., Z. Bian, M. Hammar, W. D. Sierralta, and S. Normark. 1998. Curli fibers are highly conserved between Salmonella typhimurium and Escherichia coli with respect to operon structure and regulation. J. Bacteriol. 180:722-731.

20. Ryu, J. H., and L. R. Beuchat. 2005. Biofilm formation by Escherichia coli $\mathrm{O} 157: \mathrm{H} 7$ on stainless steel: effect of exopolysaccharide and curli production on its resistance to chlorine. Appl. Environ. Microbiol. 71:247-254.

21. Silagyi, K., S. H. Kim, Y. M. Lo, and C. I. Wei. 2009. Production of biofilm and quorum sensing by Escherichia coli $\mathrm{O} 157: \mathrm{H} 7$ and its transfer from contact surfaces to meat, poultry, ready-to-eat deli, and produce products. Food Microbiol. 26:514-519.

22. Solano, C., B. García, J. Valle, C. Berasain, J. M. Ghigo, C. Gamazo, and I. Lasa. 2002. Genetic analysis of Salmonella enteritidis biofilm formation: critical role of cellulose. Mol. Microbiol. 43:793-808.

23. U.S. Department of Agriculture, Food Safety and Inspection Service (FSIS). May 2012. Compliance guideline for establishments sampling beef trimmings for Shiga toxin-producing Escherichia coli (STEC) organisms or virulence markers. Available at: http://www.fsis. usda.gov/wps/wcm/connect/e0f06d97-9026-4e1e-a0c2-1ac60b836fa6/ Compliance_Guide_Est_Sampling_STEC_0512.pdf?MOD=AJPERES. Accessed 25 June 2014.

24. Wang, R., J. L. Bono, N. Kalchayanand, S. Shackelford, and D. M. Harhay. 2012. Biofilm formation by Shiga toxin-producing Escherichia coli $\mathrm{O} 157: \mathrm{H} 7$ and Non-O157 strains and their tolerance to sanitizers commonly used in the food processing environment. $J$. Food Prot. 75:1418-1428.

25. Wang, R., N. Kalchayanand, J. W. Schmidt, and D. M. Harhay. 2013. Mixed biofilm formation by Shiga toxin-producing Escherichia coli and Salmonella enterica serovar Typhimurium enhanced bacterial resistance to sanitization due to extracellular polymeric substances. $J$. Food Prot. 76:1513-1522.

26. Zhang, M., M. M. O'Donoghue, T. Ito, K. Hiramatsu, and M. V. Boost. 2011. Prevalence of antiseptic-resistance genes in Staphylococcus aureus and coagulase-negative staphylococci colonising nurses and the general population in Hong Kong. J. Hosp. Infect. 78:113-117.

27. Zogaj, X., M. Nimtz, M. Rohde, W. Bokranz, and U. Römling. 2001. The multicellular morphotypes of Salmonella Typhimurium and Escherichia coli produce cellulose as the second component of the extracellular matrix. Mol. Microbiol. 39:1452-1463. 